15

\title{
Определение модуля упругости композиционной керамики на основе SiC
}

\author{
(C) М.В. Кияшко ${ }^{1}$, П.С. Гринчук ${ }^{1, \uparrow, ~ Т . А . ~ К у з н е ц о в а ~}{ }^{1}$, А.П. Крень ${ }^{2}$, Н.М. Abuhimd $^{3}$ \\ ${ }^{1}$ Институт тепло- и массообмена им. А.В. Лыкова НАН Беларуси, Минск, Беларусь \\ ${ }^{2}$ Институт прикладной фризики НАН Беларуси, Минск, Беларусь \\ ${ }^{3}$ National Nanotechnology Research Center King Abdulaziz City for Science and Technology, Riyadh, Saudi Arabia \\ I E-mail: gps@hmti.ac.by
}

Поступило в Редакцию 18 сентября 2020 г.

В окончательной редакции 14 октября 2020 г.

Принято к публикации 30 октября 2020 г.

На основе двух независимых методик определен модуль Юнга гетерофазной композиционной карбидокремниевой керамики с различным соотношением фаз. Продемонстрирована применимость модели Фойгта-Рейсса-Хилла для расчета эффективного модуля Юнга по измеренным свойствам компонентов керамики. Установлено, что расчетные данные и результаты независимых измерений методом динамического индентирования имеют близкие значения. При этом показано, что преимуществом расчетной методики является меньший размах полученных значений модуля Юнга. В то же время для ее применения требуется проведение дополнительных измерений состава керамики и механических свойств компонентов.

Ключевые слова: керамика, карбид кремния, модуль упругости, наноиндентирование, динамическое индентирование.

DOI: 10.21883/PJTF.2021.03.50577.18551

Керамика из карбида кремния является перспективным материалом благодаря хорошему сочетанию физико-механических свойств. В то же время высокие прочность и твердость материала накладывают ограничения на методы его характеризации. Так, классический способ определения модуля Юнга металлов и пластмасс по удлинению стержня при одноосном растяжении [1] практически неприменим для керамики из-за малости деформаций во всем диапазоне нагрузок. Кроме того, для стандартных испытаний на растяжение требуется подготовка образцов сложной формы [2], что затруднительно в случае карбидокремниевой керамики из-за ее плохой обрабатываемости. Другой статический метод определения модуля Юнга, основанный на измерении прогиба образца под нагрузкой, стандартизован для керамики [3], однако требует дорогостоящего оборудования для прецизионного измерения прогиба.

Для определения модуля Юнга керамических материалов наиболее эффективными являются методы индентирования [4] и ультразвукового измерения фазовых скоростей продольной и поперечной звуковых волн [5]. Надежный результат ультразвуковой диагностики композита возможен только при корректировках, учитывающих акустическую неоднородность материала [6]. Для композитов этот метод может приводить к большим погрешностям измерений [7].

Метод инструментального индентирования позволяет с высокой точностью определить локальные механические свойства материала. Эффективный модуль Юнга гетерофазного композита может быть непосредственно измерен, если площадь контакта индентора с поверхностью существенно превышает характерный масштаб структурной неоднородности. В обратном случае, когда воздействие индентора сосредоточено в пределах однородного достаточно крупного кристаллита, возможно измерение модуля Юнга каждого компонента по отдельности. Если при этом известны концентрации компонентов композитной керамики, то ее упругие свойства могут быть рассчитаны на основе теории эффективного модуля [8]. Такой расчет дает верхнюю и нижнюю границы диапазона значений модуля Юнга. В ряде случаев эти границы настолько близки, что оценка оказывается точнее результатов измерений [9]. Прямые инструментальные измерения позволяют определить модуль упругости плотного $\mathrm{SiC}$ с точностью порядка 10\%, а при пористости более $1 \%$ - с точностью порядка $15 \%$ [10]. Все описанное делает актуальной разработку методики измерения модуля упругости высокопрочной композитной керамики, не предъявляющей высоких требований к качеству подготовки образцов.

Цель настоящей работы - измерение модуля Юнга композиционной карбидокремниевой керамики, получаемой по технологии реакционного спекания $[11,12]$, и сопоставление различных методик определения данного модуля. Технология позволяет варьировать содержание $\mathrm{SiC}$ в керамике и тем самым контролировать свойства композита.

Разработанная технология реакционного спекания детально описана в [11]. При формовании заготовок методом шликерного литья использовались порошки карбида кремния марок М50 и М5 со средним размером частиц 50 и $5 \mu \mathrm{m}$ соответственно, соотношение фракций составляло 5:3. Четыре одинаково сформованные заготовки пропитывались бакелитовым лаком ЛБС-1. Количество 

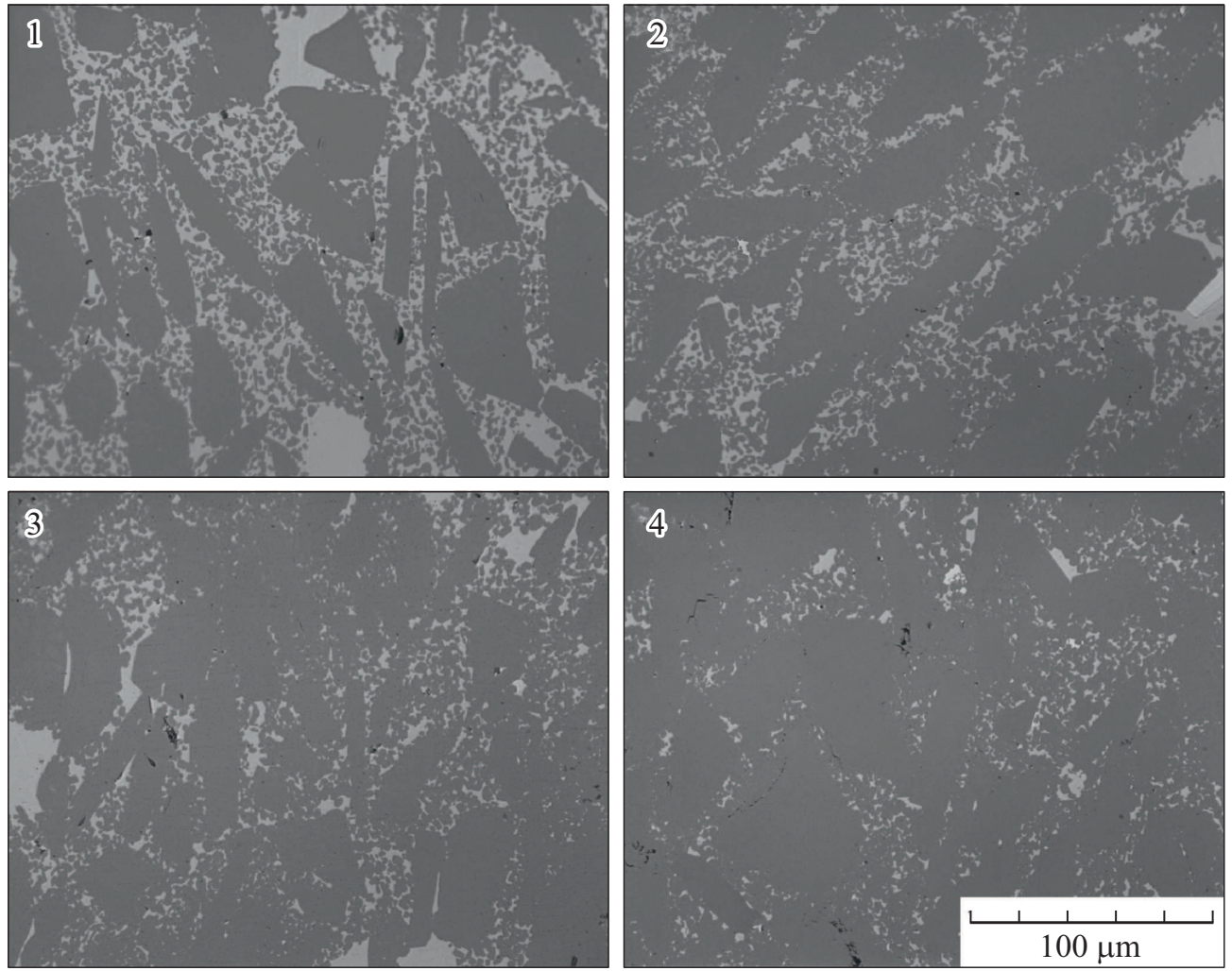

Рис. 1. Микроснимки шлифов образцов № 1-4 карбидокремниевой керамики.

пропиток варьировалось для получения различного количества углерода в порах. Реакционное спекание керамики проводилось в вакуумной печи при температуре $1800^{\circ} \mathrm{C}$. В результате химической реакции кремния с углеродом в порах каждой заготовки образовалось различное количество вторичного карбида кремния, связывающего частицы $\mathrm{SiC}$ исходного материала. Оставшееся поровое пространство заполнилось кремнием. Четыре конечных образца керамики различались соотношением $\mathrm{SiC}$ и кремния. Образцы обозначены № 1-4 по возрастанию содержания карбида кремния.

Объемные концентрации $\mathrm{SiC}$, кремния и остаточных пор определялись с помощью цифровой обработки микроснимков шлифованной поверхности, сделанных с помощью оптического микроскопа МИ-1 (Планар) с объективом $50^{\times}$. Количество микроснимков для каждого образца составляло не менее 100 с общей анализируемой площадью не менее $5 \mathrm{~mm}^{2}$. По найденным концентрациям рассчитывались значения средней плотности композита, которые сверялись с результатами измерений гидростатическим способом. Относительная погрешность гидростатических измерений плотности составила $1.8 \%$.

Определение модуля Юнга проводилось с применением двух независимых методик. В первом случае измерения выполнялись прямым способом с помощью установки для динамического индентирования на базе прибора ИСУМ-1 по методике динамического инденти- рования [13], внесенной в стандарт по неразрушающему контролю СТБ 2495-2017. Применялся твердосплавный сферический наконечник с радиусом $2.0 \mathrm{~mm}$. Диаметр контактного отпечатка при испытаниях составлял $230-420 \mu \mathrm{m}$, что по меньшей мере в 5 раз превышало характерный масштаб структурной неоднородности керамики. Для каждого образца проводилось не менее десяти измерений.

Второй вариант предусматривал измерение модуля Юнга фаз $\mathrm{SiC}$ и кремния методом квазистатического наноиндентирования (НИ) с последующим расчетом эффективного модуля Юнга композита. Измерения проводились с использованием инструмента Hysitron TI 750 Ubi с алмазным индентором Берковича с paдиусом закругления около $150 \mathrm{~nm}$ в диапазоне нагрузок 3-10 $\mathrm{mN}$.

На рис. 1 показаны микроснимки шлифов четырех образцов. Основная фаза $\mathrm{SiC}$ характеризуется крупными (около $50 \mu \mathrm{m}$ ) частицами с выраженной осколочной формой и более округлыми мелкими $(\sim 5 \mu \mathrm{m})$ частицами темно-серого цвета, равномерно распределенными в плоскости шлифа. Светлые области между частицами $\mathrm{SiC}$ соответствуют фазе кремния. Остаточные поры выглядят на снимках как черные точечные включения (по $1-2$ на площади $200 \times 250 \mu \mathrm{m}$ ). Они имеют размеры порядка микрометра, и их концентрация мала. Тем не менее пористость учитывается при анализе для повышения точности результатов. 
Компонентный состав и средняя плотность образцов карбидокремниевой керамики (значения округлены до последней значащей цифры)

\begin{tabular}{|c|c|c|c|c|}
\hline \multirow{2}{*}{ Параметр } & \multicolumn{4}{|c|}{ Номер образца } \\
\hline & 1 & 2 & 3 & 4 \\
\hline 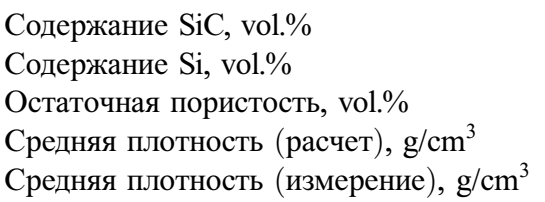 & $\begin{array}{c}78 \\
21 \\
0.5 \\
3.01 \\
3.02\end{array}$ & $\begin{array}{c}86 \\
14 \\
0.1 \\
3.08 \\
3.09\end{array}$ & $\begin{array}{c}91 \\
9 \\
0.7 \\
3.11 \\
3.10\end{array}$ & $\begin{array}{c}93 \\
5 \\
1.3 \\
3.12 \\
3.14\end{array}$ \\
\hline
\end{tabular}

На микроснимках наблюдается фракционная неоднородность карбида кремния, унаследованная от фракционного состава исходного материала (крупные частицы M50 перемежаются частицами М5). Этим обусловлен характерный масштаб микроструктуры керамики $\sim 50-100 \mu \mathrm{m}$. Концентрация $\mathrm{SiC}$ повышается с увеличением номера образца. Объемное содержание $\mathrm{SiC}$, кремния и пор для всех образцов приведено в таблице вместе с рассчитанными и измеренными значениями средней плотности. Расчет сделан при допущении, что поры не содержат остаточного углерода. Хорошее совпадение расчетных и измеренных значений плотности (разница $3 \%$ ) свидетельствует об однородности материала на поверхности шлифа и в объеме каждого образца.

Модуль Юнга разных политипов карбида кремния различается на $\sim 3 \%$, а плотность - на доли процента $[10]$, поэтому в данной работе различия политипов не учитываются. Кремний при нормальных условиях существует в единственной кубической модификации и имеет высокую анизотропию упругих свойств [14]. Исследуемая керамика характеризуется равномерным распределением случайно ориентированных зерен (рис. 1), поэтому фаза кремния рассматривается как поликристаллическая и макроскопически изотропная.

Эффективные модули упругости (модуль сдвига $G$ и объемный модуль $K$ ) композитного материала могут быть найдены путем осреднения соответствующих модулей всех компонентов [8]. Среди существующих моделей осреднения подходы Фойгта и Рейсса являются наиболее простыми и универсальными [9]. Они позволяют определить соответственно верхнюю и нижнюю границы эффективных значений для композита без рассмотрения особенностей его микроструктуры, основываясь только на соотношениях компонентов.

Подход Фойгта предполагает однородные деформации в материале [8]. Верхняя граница $M_{\mathrm{V}}$ модуля упругости (модуля сдвига или объемного модуля) композита определяется правилом смешения фаз

$$
M_{\mathrm{V}}=\sum c_{i} M_{i},
$$

где $c_{i}$ и $M_{i}-$ соответственно объемная доля и модуль упругости $(G$ или $K) i$-го компонента. Модель Рейсса предполагает однородные напряжения [9] и дает нижнюю границу $M_{\mathrm{R}}$ :

$$
\frac{1}{M_{\mathrm{R}}}=\sum c_{i} \frac{1}{M_{i}} .
$$

Среднее арифметическое значений $M_{\mathrm{V}}$ и $M_{\mathrm{R}}$ принимают за эффективный модуль композита [9] и называют средним Фойгта-Рейсса-Хилла $\left(M_{\mathrm{VRH}}\right)$

$$
M_{\mathrm{VRH}}=\frac{M_{\mathrm{V}}+M_{\mathrm{R}}}{2} .
$$

Формулы (1)-(3) применимы для осреднения модулей $K_{i}$ и $G_{i}$, которые выражаются через модуль Юнга $E_{i}$ и коэффициент Пуассона $v_{i}$ соответствующего компонента с помощью известных соотношений

$$
K_{i}=\frac{E_{i}}{3\left(1-2 v_{i}\right)}, \quad G_{i}=\frac{E_{i}}{2\left(1+v_{i}\right)} .
$$

По осредненным модулям $K_{\mathrm{VRH}}$ и $G_{\mathrm{VRH}}$ рассчитывается эффективный модуль Юнга

$$
E_{\mathrm{VRH}}=\frac{9 K_{\mathrm{VRH}} G_{\mathrm{VRH}}}{3 K_{\mathrm{VRH}}+G_{\mathrm{VRH}}} .
$$

В случае пористого композита с небольшим количеством пор может применяться модель Фойгта-Рейсса-Хилла для плотного композита с последующим учетом пористости при помощи эмпирической зависимости модуля Юнга $E_{p}$ от объемной доли пор $V_{p}[10]$ :

$$
E_{p}=E_{\mathrm{VRH}} \exp \left(-3.57 V_{p}\right) .
$$

Для расчета по модели (1)-(6) взяты концентрации из таблицы, справочные значения коэффициента Пуассона $\mathrm{SiC}(0.18)$ [10], поликристаллического кремния $(0.22)$ [14] и значения модуля Юнга, определенные методом НИ для всех фаз каждого образца.

На рис. 2 показаны характерные кривые индентирования в координатах нагрузки $F$ и глубины вдавливания индентора $h$. Кривые, полученные при максимальных нагрузках 3 и $10 \mathrm{mN}$, имеют подобную форму и совпадающие участки нагружения. Измеренный модуль Юнга кремниевой фазы составляет $190 \pm 10 \mathrm{GPa}$, фазы $\mathrm{SiC}-$ $470 \pm 30 \mathrm{GPa}$. Указанные погрешности определяются в 


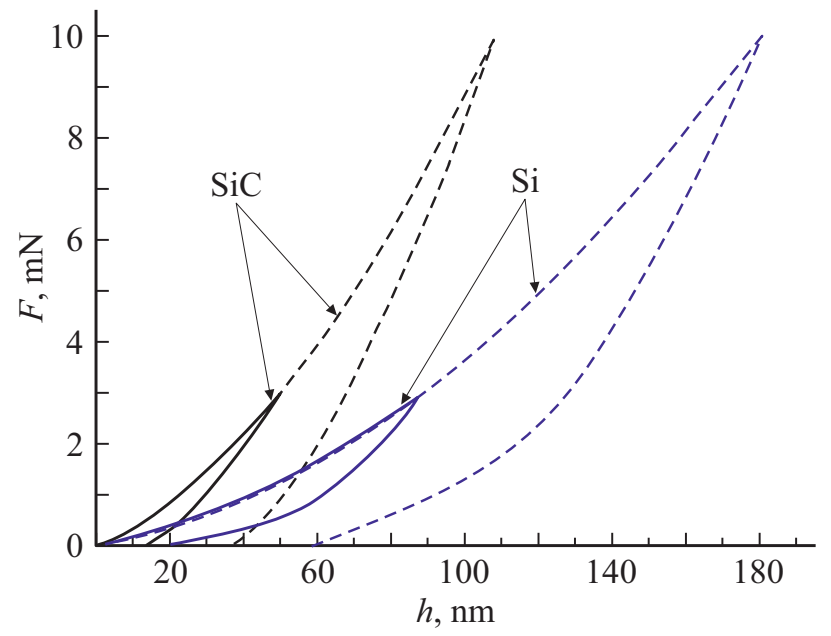

Рис. 2. Характерные кривые индентирования при максимальной нагрузке $3 \mathrm{mN}$ (сплошные линии) и $10 \mathrm{mN}$ (штриховые линии).

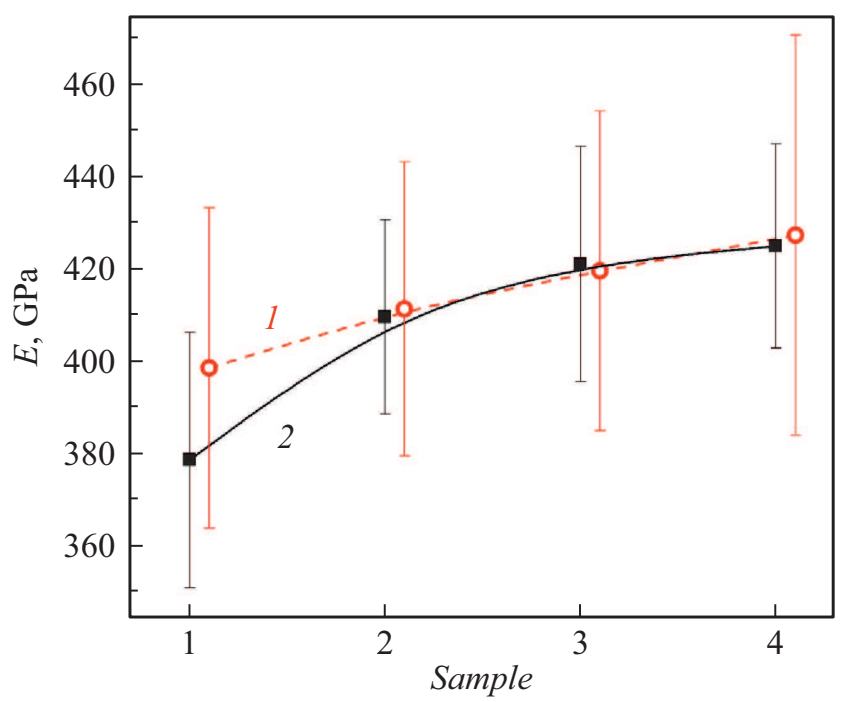

Рис. 3. Эффективный модуль Юнга образцов карбидокремниевой керамики, измеренный методом динамического индентирования (1) и рассчитанный по экспериментальным данным НИ отдельных фаз (2).

основном статистическим разбросом величин в различных участках образцов. Результаты расчетов эффективного модуля Юнга показаны на рис. 3 совместно с результатами измерений методом динамического индентирования.

Результаты, полученные двумя независимыми методами, хорошо согласуются (рис. 3). При определении модуля Юнга метод динамического индентирования на базе ИСУМ-1 имеет преимущество в качестве экспресс-метода, не требующего анализа состава керамики, ее пористости и механических свойств отдельных компонентов. Другой метод, основанный на модели Фойгта-Рейсса-Хилла, характеризуется меньшими погрешностями по сравнению с прямым измерением и позволяет обнаружить малое увеличение модуля Юнга с ростом концентрации $\mathrm{SiC}$ в керамике, а также найти модуль сдвига и объемный модуль. Этот метод дает более детальную информацию о механических свойствах материала.

\section{Финансирование работы}

Работа выполнена при поддержке King Abdulaziz City for Science and Technology (Саудовская Аравия).

\section{Конфликт интересов}

Авторы заявляют, что у них нет конфликтов интереcoB.

\section{Список литературы}

[1] И.А. Биргер, Р.Р. Мавлютов, Сопротивление материалов (Наука. М., 1986).

[2] Металлы. Методы испытаний на растяжение. ГOCT 1497-84 (ISO 6892-84) (Стандартинформ, М., 2005).

[3] Материалы керамические электротехнические. Методы испытаний. ГОСТ 24409-80 (Стандартинформ, М., 2005).

[4] J.E. Zorzi, C.A. Perottoni, Mater. Sci. Eng. A, 574, 25 (2013). DOI: 10.1016/j.msea.2013.03.008

[5] C. Reynaud, F. Thevenot, T. Chartier, J.-L. Besson, J. Eur. Ceram. Soc., 25, 589 (2005). DOI: $10.1016 /$ j.jeurceramsoc.2004.02.009

[6] А.А. Карабутов, Т.Б. Подымова, Е.Б. Черепецкая, ПМТФ, 54 (3), 181 (2013).

[7] К.Т. Тажибаев, М.Ж. Ормонов, Проблемы современной науки и образования, 9 (91), 52 (2017).

[8] Б.Е. Победря, Механика композиционных материалов (МГУ, М., 1984).

[9] G. Grimvall, Thermophysical properties of materials (Elsevier Science B.V., Amsterdam, 1999).

[10] L.L. Snead, T. Nozawa, Y. Katoh, T.S. Byun, S. Kondo, D. Petti, J. Nucl. Mater., 371, 329 (2007). DOI: $10.1016 /$ j.jnucmat.2007.05.016

[11] P.S. Grinchuk, M.V. Kiyashko, H.M. Abuhimd, M.S. Alshahrani, M.O. Stepkin, V.V. Toropov, A.A. Khort, D.V. Solovei, A.V. Akulich, M.D. Shashkov, M.Yu. Liakh, J. Eur. Ceram. Soc., 38, 4815 (2018). DOI: $10.1016 /$ j.jeurceramsoc.2018.07.014

[12] П.С. Гринчук, Х. Абухимд, А.В. Акулич, М.В. Кияшко, Д.В. Соловей, М.О. Степкин, В.В. Торопов, М.Д. Шашков, А.А. Хорт, М.Ю. Лях, Докл. НАН Беларуси, 63 (2), 223 (2019). DOI: 10.29235/1561-8323-2019-63-2-223-234

[13] А.П. Крень, Т.А. Протасеня, Дефектоскопия, № 7, 51 (2014). [Пер. версия: 10.1134/S1061830914070079].

[14] M.A. Hopcroft, W.D. Nix, T.W. Kenny, J. Microelectromech. Syst., 19 (2), 229 (2010).

DOI: 10.1109/JMEMS.2009.2039697 